\title{
Analysis of Risk Management Plan of Finance Section
}

\author{
Jiaming Huang ${ }^{1 *}$
}

\author{
${ }^{1}$ University of California, Santa Cruz \\ ${ }^{*}$ Corresponding author: Email: huangjiaming1998@gmail.com
}

\begin{abstract}
This paper mainly uses the Nanhai District, Foshan City, maternal and child health care hospital as an example, for its financial analysis of the basic situation, and supplemented by financial risk management comparison, the company in this area problems, Reason and the way to solve the problem.

For the financial risk, on the one hand, it can enhance the content of relevant research to promote and promote the research and development of related topics; on the other hand, it is beneficial to enrich the theoretical basis of financial risk management. In theory and practice have important significance and role.
\end{abstract}

Keywords: Risk management, Plan, Finance section

\section{INTRODUCTION}

The purpose of the study: the financial sector has always been one of the company's core business, if the financial sector problems, then the company's overall will be greatly damaged. Financial risk management is to avoid such a situation and the emergence of a management. The purpose of this paper is to analyze the problems of Maternal and Child Health Hospital in Nanhai District of Foshan City on the basis of theoretical research, and to clarify the importance of corporate financial risk management and make suggestions on its financial risk management.

\section{THE STATUS QUO}

\subsection{Research Status Abroad}

Foreign research on the relevant topics of comparative molding, the beginning is also relatively early. Whether it is theoretical research or practical application, have formed a unique and relatively complete system. But relatively speaking, foreign research of the same type more biased in favor of the enterprise itself, the analysis of the main body is the enterprise itself, which is a free foreign market economy has a great relationship. However, in the development of foreign free market economy, there are many different situations, which also led to a lot of foreign scholars for the financial risk management research appeared a refinement of the phenomenon, a large number of branches, the formation of a different theory. But the most basic is to say that the American doctrine and the
British doctrine, many of the relevant factions of the theory are developed from this. The biggest difference between American doctrine and British doctrine is the difference in the focus of the study. American scholars focus on risk management, while the British scholar is the relevant processing procedures. From the current research situation, foreign financial risk management will focus on the first strategy, the theoretical part is relatively weak.

This research originated in the early last century, in the fifties and sixties has been widely promoted, after being accepted by the public has been widely developed and popularized. This is also the beginning of the theory of foreign financial risk research. At the end of the last century, some long-term enterprises began to carry out the relevant financial risk management department set, which on the other hand is to promote the financial risk management research and development.

\subsection{Status of Domestic Research}

For domestic research, pay more attention to the enterprise as the main body, taking into account the market, policy, industry and other aspects of a comprehensive study. On the one hand, the domestic enterprises by the policy impact is relatively large; the other hand, the domestic financial management system is still relatively mature, biased in theory.

China's financial risk management research started relatively late, in the mid-80s began to talk about the system, but the focus for the theoretical part of the practical problems for the enterprise is relatively weak. 
On the status quo of research, China's research results can be summed up as a theoretical study within the enterprise and from the corporate environment for financial risk management research.

\subsection{Research Methods}

\subsubsection{Research ideas}

The research of this paper is based on the theory, the analysis of the relevant concepts, supplemented by Nanhai District, Foshan City, Maternal and Child Health Hospital of the case of the case analysis, the conclusions found that the problem and put forward the relevant countermeasures.

\subsubsection{Research methods}

The main research methods of this paper are literature inquiry method and field investigation method.

On the literature survey method is to find the library books to carry out, in addition to the publication of the relevant topics in recent years, journals and so on. And the field investigation law is in the holidays when the Foshan Nanhai District Maternal and Child Health Hospital Company conducted a depth of its case investigation, and its related staff were interviewed[1].

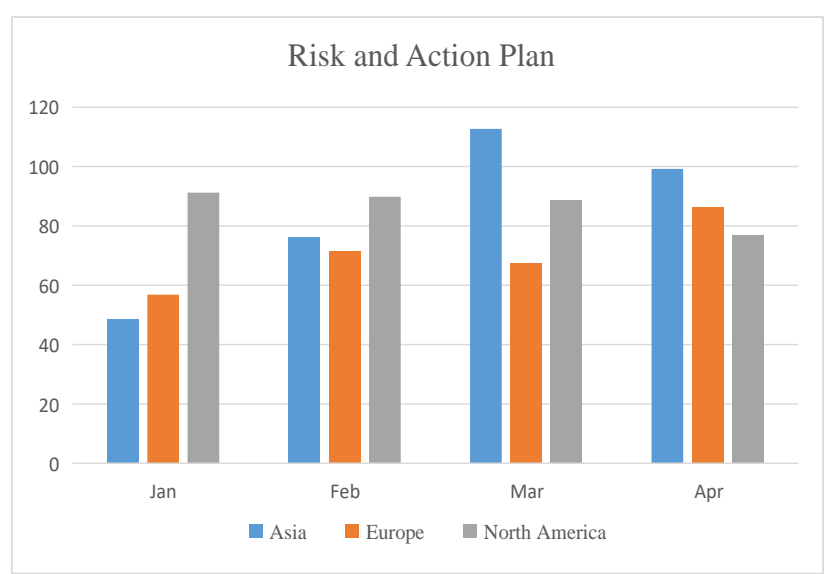

Figure 1 Risk management

Table 1. Risk and Action Plan

\begin{tabular}{|l|l|l|}
\hline $\begin{array}{l}\text { Risk } \\
\text { description }\end{array}$ & $\begin{array}{l}\text { Risk } \\
\text { assessment }\end{array}$ & Action planning \\
\hline Description & Impact & Contingency Plan \\
\hline
\end{tabular}

\section{THE THEORETICAL BASIS OF FINANCIAL RISK MANAGEMENT}

\subsection{The Definition of Financial Risk}

Financial risk management is part of risk management. The management function of this special means is mainly controlled by the experience of predecessors' risk management and the development of modern scientific and technological achievements. In addition, the main part of financial risk management is in financial The activities of the main body of the various possible risks, challenges, choose to predict, through the basis of this relevant information analysis, identification, scheduling and comparison, at the same time set several solutions and find a The most reasonable way to prevent and grasp the risks that may be met. The choice of this method is the standard of economic rationality, the purpose is to ensure that the daily activities of financial activities, to avoid unnecessary loss of property to help enterprises get more profits.[2]

(Ii) the development and classification of financial risks

\subsubsection{The generation of financial risk}

In 1949, financial risk management was originally considered one of the six management functions of the French management theorist Henry Feiyao. The background of this theory is the analysis of the background of the industrial revolution, in Henry's "general and industrial revolution" mentioned "risk management activities is one of the basic activities of enterprises" but we should note that, due to The context of the times is different, and the conditions and conditions of society are different. Therefore, the scope of the "security activities" mentioned in the book is much smaller than that in the present situation.

With the passage of time and social development, people's understanding of financial risk management is also deepening, in the "financial risk management," a book, the US risk management scientist Gleason will risk management of the content category as Enterprise risk measurement, the establishment of models to assess, set up a professional team in order to control the business can foresee the risks and losses.

In 1964, five elements of corporate risk management were identified in the book "Risk Management and Insurance", completed by American risk management expert Williams and Hans, namely, identifying risk tasks, assessing risks, and controlling risk, Risk financing, and corporate risk management information. (Benjamin Klein,2012) In addition, the well-known risk management consultant Felix and Jovi also put forward their own views on the elements of risk management, they will be the entire enterprise into an information "system", the use of appropriate information technology to the enterprise Financial risk management and the avoidance of its losses[3].

\subsection{Financial Risk Classification}

The general theoretical understanding of financial risk management in China is to look at the company as 
the main body of the economy and to measure and analyze the subject and take appropriate action to avoid the foreseeable risk loss in order to ensure the economic and vested benefits of the enterprise. In the classification of financial risk management, it can be roughly divided into five categories, namely inventory management risk, liquidity risk, financing risk, investment risk, operational risk. Next, I will briefly introduce these aspects:

Inventory management risk: the lack of awareness of the lack of inventory management system and the resulting problems such as cargo turnover. Liquidity risk: refers to the ability to pay but for various reasons no way to timely replenishment of funds. Financing risk: the firm's debt and the variability of the income.Investment risk: the risk of possible investment in the business process. Operational risk: the risk that a business may occur in its daily business activities.

\subsection{The Significance of Financial Risk Management Research}

The significance of the study of financial risk management is mainly analyzed by the following points

\subsubsection{Improve the status of financial management}

The core of the enterprise management is the financial, for the enterprise to carry out effective financial risk management can be within the enterprise for the financial situation to control, on the one hand can be the daily financial flow of enterprises to take reasonable control, on the other hand can be a reasonable analysis of the status quo of the enterprise, So as to choose the most reasonable way.

\subsubsection{To help enterprises make reasonable decisions}

If the enterprise wants to go long, there must be a good decision, the financial risk management can effectively analyze the status quo of the enterprise, so as to help the management of enterprises to make reasonable decision-making to help enterprises to a flatter development path.

\subsubsection{Effective risk avoidance}

The risks faced by an enterprise are sometimes not only from the competition of the opponent, but also the coordination problem within the enterprise. Therefore, the effective financial risk management for the risks faced by the enterprise can avoid these losses properly. A necessary and important business management tool.

Nanhai District, Foshan City, Maternal and Child Health Hospital Electronic Technology Co., Ltd. of the scope of services from abroad to expand abroad, its products include the United States, Europe, Southeast
Asia and other 56 countries and Hong Kong, Macao and Taiwan regions. In the product research and development, Foshan Nanhai Maternal and Child Health Hospital is committed to independent research and development, the future direction of the development of enterprises is to create their own goals, the current enterprises have fully equipped with software from hardware to the whole process of independent research and development capabilities, Speed and update the quality, has become the line of R \& D strength of the strongest one of several enterprises, in addition, the company also focused on new products and projects, with a variety of technical patents, we can see, Foshan City Nanhai District Maternal and Child Health Hospital development trend is high-tech, independent research and development direction[4].

\subsection{Enterprise Management for the Management of Funds to Master the Degree of Analysis}

The management of the enterprise in the whole economic activities, like the captain of the same vessel, only the captain has a good decision to ensure that enterprises are not among the sailing by the wind and waves, but Foshan Nanhai District Maternal and Child Health Hospital Management for the degree of capital flows to the enterprise and how much, I made a questionnaire, the specific results are as follows: nearly half of the work of the relevant financial management staff usually for the understanding of the flow of funds only through the subordinate data table, In this part of the crowd, some people do not even have the relevant background of professional knowledge. In addition, the survey also found a situation is the internal nepnea serious, engaged in the financial sector staff may not have the relevant skills, but because the "nepotism" into the financial sector to work this comfortable. In another question of the questionnaire also shows that in the management, the enterprise in recent years, the specific operating conditions do not understand the management update data is slow, the status of the enterprise is not a good understanding. As the enterprise's decision-making is finalized through management discussions, so the management of information updates and financial understanding of the company is extremely important, in this regard, Foshan Nanhai District Maternal and Child Health Hospital Company has some problems to be solved.

\subsubsection{The financial sector for the capital to grasp the degree of analysis}

In the analysis of the financial department of the Maternal and Child Health Hospital of Nanhai District of Foshan City, I also adopted a questionnaire survey, on the one hand this way can use anonymous method to facilitate more real information; Aspects of this method 
quickly and quickly. And then through the finishing survey I found a phenomenon, that is, Nanhai District, Foshan City, Maternal and Child Health Hospital of the company's financial sector for the level of capital flow to the level of missing, on the one hand because the financial sector within the division of labor is too fine, resulting in people between The lack of communication between departments, departments have been hampered by cooperation, but also makes the human and material resources are a little unnecessary waste; the other is the corporate accounts open transparency is not enough, this approach makes the financial sector some measures powerless, there is no way to find the problem, Cannot provide a better way of enterprise development, has become buried in the enterprise financial risk management in the time bomb. Therefore, the appropriate strengthening of the links between the financial sector to ensure that the accounts transparent and open, are for the enterprise financial risk management of the necessary measures.

\subsubsection{Management objectives are not clear}

Management's financial goals for the company's setting are not clear. The goal here is not clear that the two aspects, one is the enterprise's external strategic objectives, one is the enterprise's internal financial goals. In the enterprise's foreign strategic objectives, Foshan Nanhai District Maternal and Child Health Hospital, although it is a high-tech enterprises for the legislature, but for today's background, the strategic objectives of enterprise development is not clear. First because of the rapid development of social technology. It is precisely because of the rapid development of Internet technology, resulting in high-tech industry updates are faster and faster. Second, because more and more competitors appear, we control the technology is not much difference, so the focus is self-development, but Foshan Nanhai District Maternal and Child Health Hospital Company in recent years to invest in independent research and development of financial resources and no great advantage The In the enterprise's internal financial goals, refers to the daily business activities of enterprises, from the above Table I and Table II, we can find, Foshan Nanhai District Maternal and Child Health Hospital of the company's internal financial has been a very serious problem, The financing difficulties of enterprises and the investment and financing can not fill the current loopholes, are the need to solve the problem. (Rajan, 2012) If a company's financial objectives clear, the financial department of the scheduling rigorous, it will not happen this situation, and in the above survey, we can see in the financial sector, the understanding of financial risk management is not deep, There is no relevant professionals is also difficult for the smooth development of enterprises.

\subsubsection{The management method is incorrect}

In the Nanhai District, Foshan City, maternal and child health care companies to investigate the same time, I found on the Internet that the company's accounts are not found to be very fine, no breakdown and comparison of the project, but also to the enterprise's property risk A certain obstacle. We can see that the company's approach to financial risk management is the most traditional one, and has been in use, not according to the ever-changing business changes, the relevant data update is not comprehensive, we can imagine, in the enterprise In the daily financial risk management, there are "short board effect", first of all, the method is not a correct enterprise risk management in the short board, that is, the enterprise risk management has become a short board in the enterprise, affecting the entire enterprise short Board, resulting in a huge negative effect[5].

\subsubsection{The relevant professional quality of employees is low}

The low quality of the relevant practitioners is not only reflected in the low level of professionalism, but also can be reflected in the practitioner's ability to practice low level. In Nanhai District, Foshan City, maternal and child health care company, the financial sector practitioners are through ordinary recruitment, the graduates of the work experience, the face of the actual financial problems may be handled improperly, the combination of theory and practice Good will lead to corporate financial risk is not handled properly. And Nanhai District, Foshan City, Maternal and Child Health Hospital, the company was founded when the people left, some of the enterprises are now facing the situation is not high degree of grasp, and some do not have the relevant professional background, which is leading to Nanhai District, Foshan City, women and children One of the reasons for the improper management of corporate financial risk in health care companies.

\section{CONCLUSION}

The training of the relevant personnel should not be confined to the theoretical aspects, should be placed in practice, the specific method can be used by training practitioners on-site observation and financial statements, for the existence of financial risk in the enterprise to predict and analysis. The idea of scientific decisionmaking is mainly dependent on the management of the enterprise, the former mentioned in the business managers to describe the words of the sea is inside the helmsman, but in this, the role of the manager is equivalent to the captain. For the managers of enterprises, people are the core strength of enterprise development, including on the business leaders, down to any employee of the company, but also includes the pursuit of the enterprise customers. To solve the problems within the enterprise itself, the enterprise leaders should formulate 
appropriate and reasonable development strategy model, formulate the strategic objectives of the enterprise, enhance the core cohesion and competitiveness of the enterprise, evaluate and judge the internal and external environment of the enterprise, and make scientific and rational decision-making.

\section{REFERENCES}

[1] Aghion P,Tirole J.Foromal and Real Authority in Oaganizations . Journai of Politiles .2012
[2] Hammer M,Champy J.Reengineering the Corporation: A Manifesto for Business Revolution. Journal of Women s Health. 2013

[3] Rajan RG,Zingales L.Power in a Theory of the Firm. Quarterly Journal . 2012

[4] Benjamin Klein.Fisher-General Motors and the Nature of the Firm. Journal of Law and Economics. 2012

[5] Tirole J.Corporate Economy. . 2013 